\title{
Pseudotumor inflamatório endobrônquico: relato de caso*
}

\author{
Endobronchial inflammatory pseudotumor: a case report \\ Pablo Gerardo Sanchez ${ }^{1}$, Gabriel Ribeiro Madke², Eduardo Sperb Pilla ${ }^{2}$, Rafael Foergnes ${ }^{3}$, \\ José Carlos Felicetti ${ }^{4}$, Enio do Valle ${ }^{5}$, Geraldo Geyer ${ }^{6}$
}

\section{Resumo}

0 pseudotumor inflamatório de pulmão é uma neoplasia benigna rara que geralmente se manifesta como um nódulo pulmonar solitário. A apresentação endobrônquica é infreqüente. 0 tratamento de escolha continua sendo a cirurgia conservadora e deve-se sempre procurar obter margens livres devido à possibilidade de recidiva local. Esse artigo relata o caso de um paciente de 36 anos, com crises de sibilância e tosse, que foi submetido, com sucesso, à broncoplastia para ressecção de um pseudotumor inflamatório endobrônquico.

Descritores: Granuloma de células plasmáticas; Lesão numular pulmonar; Cirurgia.

\begin{abstract}
Inflammatory pseudotumor of the lung is a rare form of benign neoplasia and is generally characterized by a solitary pulmonary nodule. The endobronchial presentation is uncommon. Conservative surgery remains the treatment of choice, and surgeons should always strive to achieve tumor-free margins due to the possibility of local recidivism. This article reports the case of a 36-year-old male patient with recurrent attacks of wheezing and cough. The patient underwent successful bronchoplasty for the resection of an endobronchial inflammatory pseudotumor.
\end{abstract}

Keywords: Granuloma, plasma cell; Coin lesion, pulmonary; Surgery.

\section{Introdução}

Descrito originalmente como granuloma de células plasmáticas, ${ }^{(1)}$ o pseudotumor inflamatório de pulmão possui uma série de sinônimos como histiocitoma fibroso ou fibroxantoma, o que demonstra uma limitada compreensão de sua etiopatogenia. Acomete principalmente pacientes jovens e não apresenta predisposição por raça ou sexo. ${ }^{(2)}$ Apesar de sua origem desconhecida, um terço dos pacientes relatam infecção pulmonar prévia. ${ }^{(3)} 0$ nódulo pulmonar solitário é a sua forma de apresentação mais freqüente, sendo rara a forma endobrônquica.

\section{Relato de caso}

Um paciente masculino de 36 anos, não tabagista, internou-se para investigação de tosse crônica e sibilância. 0 exame físico demonstrou sibilo expiratório à direita. A radiografia simples de tórax evidenciou atelectasia do lobo inferior direito, enquanto a tomografia de tórax demonstrou a presença de uma imagem endobrônquica (Figura 1a). A broncoscopia identificou uma lesão vegetante que ocluía completamente o brônquio intermediário (Figura 1b) e a biópsia sugeriu o diagnóstico de hemangioma. 0 paciente foi estadiado sistematicamente devido à

\footnotetext{
* Trabalho realizado no Pavilhão Pereira Filho da Santa Casa de Porto Alegre; Programa de Pós-Graduação em Medicina/Pneumologia da Universidade Federal do Rio Grande do Sul - UFRGS; Disciplina de Cirurgia Torácica da Fundação Faculdade Federal de Ciências Médicas de Porto Alegre - FFFCMPA - Porto Alegre (RS) Brasil. 1. Mestre em Pneumologia pela Universidade Federal do Rio Grande do Sul - UFRGS - Porto Alegre (RS) Brasil.

2. Cirurgião Torácico do Hospital Ernesto Dornelles, Porto Alegre (RS) Brasil.

3. Acadêmico de Medicina da Fundação Faculdade Federal de Ciências Médicas de Porto Alegwre - FFFCMPA - Porto Alegre (RS) Brasil.

4. Professor Assistente de Cirurgia Torácica do Departamento de Cirurgia da Fundação Faculdade Federal de Ciências Médicas de Porto Alegre - FFFCMPA Porto Alegre (RS) Brasil.

5. Pneumologista do Hospital Moinhos de Vento, Porto Alegre (RS) Brasil.

6. Patologista do Departamento de Patologia da Santa Casa de Porto Alegre, Porto Alegre (RS) Brasil.

Endereço para correspondência: Pablo Gerardo Sánchez. Santa Casa de Porto Alegre, Pavilhão Pereira Filho, Avenida Prof. Annes Dias, 285 , $1^{\circ}$ andar, Centro, CEP 90020-090, Porto Alegre, RS, Brasil.

Tel 5551 3225-6831. E-mail: pgsanchez@gmail.com

Recebido para publicação em 24/5/06. Aprovado, após revisão, em 10/8/06.
} 

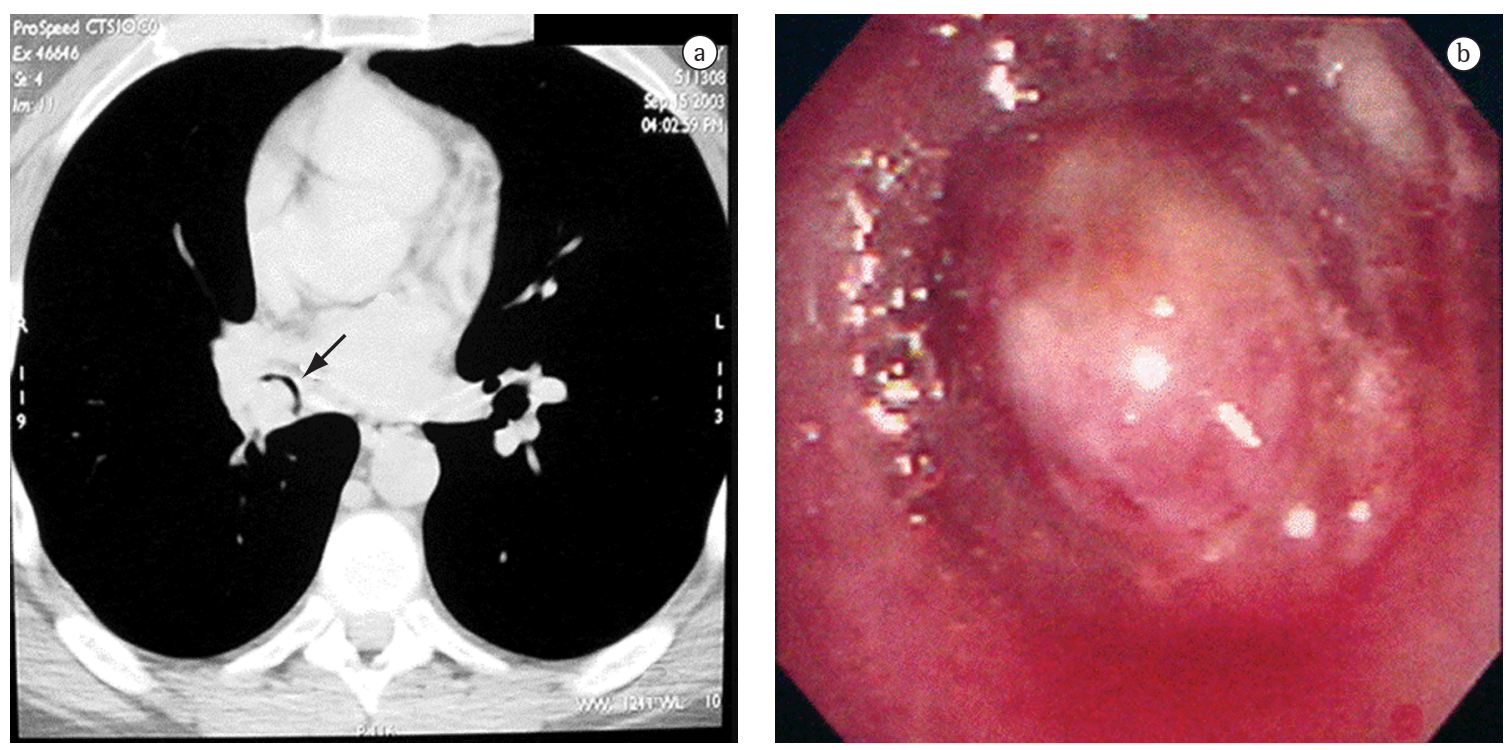

Figura 1 - Aspectos radiológicos e endoscópio: a) TC de tórax mostrando obstrução quase completa da luz do brônquio intermediário (seta); e b) Visão endoscópica do tumor.

hipótese de se tratar de uma neoplasia brônquica. Sem evidência de comprometimento loco-regional ou à distância, o paciente foi submetido a uma toracotomia lateral direita para ressecção do lobo inferior. Devido a sua extensão endobrônquica, com comprometimento do brônquio intermediário e não invasão do brônquio lobar médio, decidiu-se realizar lobectomia inferior com ressecção parcial do brônquio intermediário e uma reconstrução com

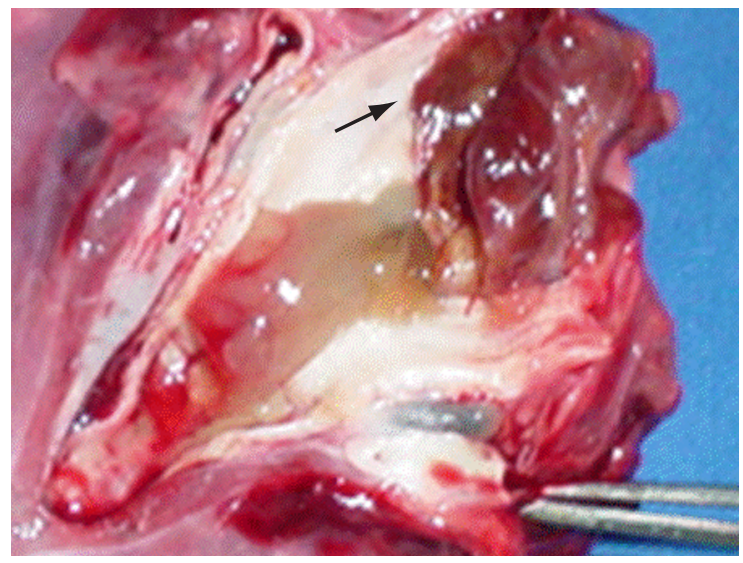

Figura 2 - Peça operatória: abertura longitudinal do brônquio lobar inferior direito mostrando origem do tumor no segmento superior (seta). Retenção distal de secreção. anastomose entre a parte proximal do brônquio intermediário e o brônquio lobar médio. 0 paciente teve uma evolução pós-operatória sem intercorrências e recebeu alta no quinto dia pós-operatório. 0 tumor originava-se no brônquio segmentar superior do lobo inferior direito (Figura 2). 0 diagnóstico anátomo-patológico foi de pseudotumor inflamatório do tipo fibrohistiocítico (Figura 3), confirmado por imunohistoquímica.

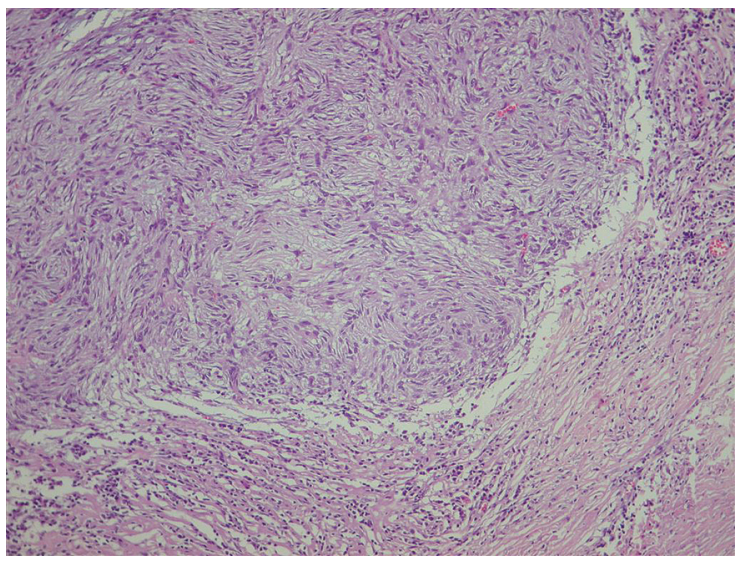

Figura 3 - Fotomicrografia mostrando área com padrão proliferativo fusocelular estoriforme, tendo ao lado área de padrão inflamatório. 


\section{Discussão}

0 pseudotumor inflamatório representa menos de $1 \%$ de todos os tumores de pulmão. ${ }^{(4)} \mathrm{A}$ idade média de apresentação é de 40 anos, sendo que $15 \%$ dos pacientes têm menos de 10 anos. ${ }^{(5)} \mathrm{A}$ maioria dos pacientes são assintomáticos, embora possam apresentar tosse, febre, hemoptise, dispnéia e bronquite crônica. Esse tipo de tumor costuma se apresentar como um nódulo pulmonar solitário ou como uma massa de contornos bem definidos, sendo muitas vezes confundido com neoplasia maligna do pulmão. A apresentação endobrônquica é rara, representando menos de $12 \%$ dos casos, e constitui a forma mais sintomática, o que leva, freqüentemente, a um diagnóstico precoce. 0 exame citológico do escarro e do lavado broncoalveolar não são diagnósticos, mas são importantes na exclusão de infecções ativas, como tuberculose ou outras neoplasias.

A histologia mostra uma proliferação local de células plasmáticas maduras e células reticuloendoteliais em um estroma de tecido de granulação sem sinais de mitoses ou atipias. Os diagnósticos diferenciais incluem hemangioma esclerosante, pseudolinfoma, proliferação maligna de células plasmáticas e granulomas infecciosos.

0 tratamento de escolha continua sendo a cirurgia conservadora, ${ }^{(1)}$ embora seu comportamento localmente agressivo obrigue eventualmente a procedimentos mais radicais, como, por exemplo, a pneumonectomia. Outros relatos da literatura ${ }^{(4,6)}$ mostram que há bons resultados quando se realiza a broncoplastia para o tratamento desses tumores. No presente caso, a proximidade com o brônquio do lobo médio assim como sua extensão dentro do brônquio intermediário exigiu a realização da broncoplastia para busca de margens livres e preservação do lobo médio. A enucleação de nódulos não é recomendada por sua chance de recidiva. ${ }^{(5)} \mathrm{A}$ radioterapia e a corticoterapia podem ser consideradas em pacientes com recidiva, em pacientes submetidos à ressecção incompleta ou em pacientes sem condições clínicas para ressecção pulmonar. ${ }^{(7,8)} 0$ prognóstico parece ser excelente quando a ressecção cirúrgica é completa. ${ }^{(1,5)}$

Concluindo, o pseudotumor inflamatório de pulmão é uma neoplasia benigna rara, localmente invasiva, geralmente assintomática, exceto em sua forma endobrônquica, e cujos aspectos clínico e radiológico sugerem outras neoplasias. Os exames pré-operatórios normalmente não são diagnósticos, sendo necessária a ressecção completa da lesão tanto para tratamento adequado quanto para um diagnóstico definitivo.

\section{Referências}

1. Cerfolio RJ, Allen MS, Nascimento AG, Deschamps C, Trastek VF, Miller DL et al. Inflammatory pseudotumors of the lung. Ann Thorac Surg. 1999;67(4):933-6.

2. Bahadori M, Liebow AA. Plasma cell granulomas of the lung. Cancer. 1973;31(1):191-208.

3. Alexiou C, Obuszko Z, Beggs D, Morgan WE. Inflammatory pseudotumors of the lung. Ann Thorac Surg. 1998;66(3):948-50.

4. Chen D, Ryan G, Edwards M. Bronchial sleeve resection for a patient with an inflammatory pseudotumor. ANZ J Surg. 2001;71(3):187-9.

5. Copin MC, Gosselin BH, Ribet ME. Plasma cell granuloma of the lung: difficulties in the diagnosis and prognosis. Ann Thorac Surg. 1996;61(5):1477-82.

6. Maeda M, Matsuzaki Y, Edagawa M, Shimizu T, Onitsuka T, Kataoka H. Successful treatment of a bronchial inflammatory pseudotumor by bronchoplasty in an 8-year-old boy: report of a case. Surg Today. 2000;30(5):465-8.

7. Shirakusa T, Kusano T, Motonaga R, Eimoto T. Plasma cell granuloma of the lung --resection and steroid therapy. Thorac Cardiovasc Surg. 1987;35(3):185-8.

8. Imperato JP, Folkman J, Sagerman RH, Cassady JR. Treatment of plasma cell granuloma of the lung with radiation therapy. A report of two cases and a review of the literature. Cancer. 1986;57(11):2127-9. 